\title{
Исследование структурных и сорбционных свойств глауконита
}

\section{Кузнецова Е.В.}

Институт химии и технологии редких элементов и минерального сырья им. И.В. Тананаева КНЦ РАН, Anamumbl,m.maslova@ksc.ru

Аннотация. Изучены структурные особенности глауконита месторождения Центральное (Тамбовская обл.). Методами химического анализа, РФА и ИК-спектроскопии показано, что преобладающим катионом в октаэдрической позиции минерала является Fe(III), что свидетельствует о малой дефектности в октаэдрах. Вместе с тем, измененность глауконита подтверждается пониженным содержанием калия и магния и в межслоевом пространстве. Изучена сорбционная способность глауконита по отношению к катионам тяжелых металлов и построен ряд селективности: $\mathrm{Zn}^{2+}>\mathrm{Mn}^{2+}>\mathrm{Cu}^{2+}>\mathrm{Co}^{2+}>\mathrm{Ni}^{2+}$.

Ключевые слова: глауконит, растворение минерала, сорбционные свойства, тяжелые металлы.

\section{Study of the structural and sorption properties of glauconite}

\section{Kuznetsova E.V.}

\section{I.V. Tananaev Institute of Chemistry and Technology of Rare Elements and Mineral Raw Materials of the} Russian Academy of Sciences Kola Science Center, Apatity, m.maslova@ksc.ru

Abstract. The structural features of glauconite from the Central deposit (Tambov region) have been studied. Based on chemical analysis, XRD, and IR spectroscopy it have been shown that the predominant cation in the octahedral sites of the mineral is Fe(III), which indicates a low defectiveness in the octahedra position of glauconite. At the same time, the alteration of glauconite is confirmed by a low content of potassium and magnesium in the interlayer region. The sorption capacity of glauconite in relation to heavy metal cations in the batch system followed the order: $\mathrm{Zn}^{2+}>\mathrm{Mn}^{2+}>\mathrm{Cu}^{2+}>\mathrm{Co}^{2+}>\mathrm{Ni}^{2+}$.

Key words: glauconite, mineral dissolution, sorption properties, heavy metal ions.

\section{Введение}

Глауконит - природный минерал, водный алюмосиликат железа, относящийся к группе диоктаэдрических гидрослюд однослойной полиморфной модификации с общей формулой: $\mathrm{K}(\mathrm{Mg}, \mathrm{Fe}, \mathrm{Al})\left[\mathrm{AlSi}_{3} \mathrm{O}_{10}\right](\mathrm{OH})_{2}$. Основной элемент структуры - трехслойный пакет, в котором между двумя алюмокремнекислородными тетраэдрами $\left[\mathrm{AlSi}_{3} \mathrm{O}_{10}\right]^{4-}$ располагается слой октаэдров. Трехслойные пакеты связываются между собой межслоевым калием, который частично замещен на воду (Глауконит в современных, нижнепалеозойских и докембрийских отложениях, 1971). Благодаря специфической морфологии, структурным особенностям и химическому составу глауконит проявляет ионообменную способность и каталитические свойства, которые определяют его применение.

Глауконит Саратовского месторождения в период с 1936 по 1948 гг. применялся на различных теплоэлектростанциях страны для снижения жесткости воды с регенерацией до 500 раз/год. Опытные испытания минерала в качестве адсорбента показали, что при использовании активированного глауконита месторождения Хмельнитчины (Украина) для очистки загрязненных вод практически полностью удаляются соединения железа и аммиака, на порядок снижает содержание нефтепродуктов (Вигдорович и др., 2016).

Установлена высокая эффективность глауконита при очищении воды от солей тяжелых металлов, ряда органических и неорганических композиций (Hao, Tsai, Huang, 1987; Martemianov и др., 2020; Naghipour и др., 2018; Shmandiy и др., 2020; Вениг и др., 2017). Можно использовать глауконит при очистке радиоактивных стоков (Bruneel и др., 2020; Stefanova, 1999). Исследованиями Ю.А. Кацнельсона с сотрудниками (Кацнельсон, Алексаньян, Волошина, 1981) установлено, что глаукониты месторождений Ростовской области являются ионообменными избирательными поглотителями долгоживущих радиоактивных изотопов Cs-137, Sr-90 и могут быть использова- 
ны для дезактивации сточных вод с повышенной радиоактивностью. В результате очистки суммарная $\beta$-активность снижается на два порядка.

Целью настоящих исследований являлось определение сорбционной способности глауконита месторождения Центральное к извлечению из растворов ионов тяжелых металлов.

\section{Методы и объекты исследования}

В качестве объекта исследований был выбран глауконит месторождения Центральное (Тамбовская обл.), который является минеральной составляющей легкой фракции рудных песков. Среднее содержание глауконита в песках месторождения составляет $49 \kappa^{*} \mathrm{M}^{-3}$. Представленная проба представляет собой тонкоизмельченную фракцию минерала (менее 0.1 мм), удельный вес $2.8 \Gamma^{\circ} \mathrm{cm}^{-3}$, твердость по минеральной шкале - 3, слабомагнитный.

Для определения растворимости элементов минерала навеску материала помещали в раствор с заданным значением $\mathrm{pH}$, которое устанавливали, добавляя растворы $0.1 \mathrm{~N} \mathrm{HCl}$ или $0.05 \mathrm{~N} \mathrm{NaOH}$. Суспензию глауконита $\left(10 \Gamma^{\cdot} \pi^{-1}\right)$ перемешивали в течение 24 ч при комнатной температуре и фильтровали через мембранный фильтр с размерами пор 0.45 мкм. Жидкую фазу анализировали с помощью атомно-адсорбционного спектрометра Perkin-Elmer 3100 (относительная погрешность измерения $\pm 3 \%)$.

При изучении сорбции выбранных ионов в статических условиях 0.5 г глауконита заливали

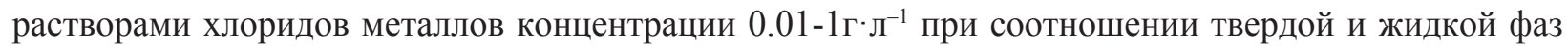
1:200 и выдерживали при температуре $22{ }^{\circ} \mathrm{C}$ и периодическом перемешивании до состояния равновесия. Величина $\mathrm{pH}$ исходных водных растворов составляла 5-5.5. После отделения минеральной части равновесная жидкая фаза анализировалась на содержание сорбата с использованием спектрофотометра Perkin-Elmer FT-IR 200 spectrometer. На основании полученных результатов рассчитывали емкость сорбента по определяемому иону (ммоль $\left.\Gamma^{-1}\right)$.

Содержания элементов в растворах определяли методом плазменной эмиссионной спектроскопии на спектрометре Shimadzu ICPE-9000 после растворения взвешенного количества образца в смеси $\mathrm{HF}, \mathrm{HNO}_{3}$ и $\mathrm{HCl}$. Дифрактограммы получали на дифрактометре Shimadzu D6000 с монохромным $\mathrm{Cu}-\mathrm{K} \alpha$ излучением $(\lambda=1.5418 \AA)$. Поверхностные свойства минерала определяли по методу БЭТ с помощью анализатора поверхности ASAP 2000. Инфракрасные спектры образцов были получены на спектрометре Nicolet 6700. SEM-изображения были получены с использованием сканирующего электронного микроскопа SEMLEO-420.

\section{Результаты и обсуждение}

Химический состав глауконита месторождения Центральное, \% мас.: $\mathrm{SiO}_{2}-52.5 ; \mathrm{Al}_{2} \mathrm{O}_{3}-9.2$; $\mathrm{MgO}-1.9 ; \mathrm{Fe}_{2} \mathrm{O}_{3}-18.2 ; \mathrm{FeO}-1.0 ; \mathrm{CaO}-1.8 ; \mathrm{K}_{2} \mathrm{O}-3.7 ; \mathrm{Na}_{2} \mathrm{O}-0.2 ; \mathrm{MnO}-0.03 ; \mathrm{P}_{2} \mathrm{O}_{5}-1.1 ; \mathrm{TiO}_{2}-2.0$; $\mathrm{ZrO}_{2}-0.12$; кварц - 16.7 .

Рентгенофазовый анализ глауконита (рис. 1) показал, что для исследуемого минерала характерны основные отражения с межплоскостными расстояниями $\mathrm{d}=4.2,3.09,3.33,2.58 \AA$ которые являются определяющими для однослойной полиморфной модификации слюд типа $1 \mathrm{M}$ (Burst, 1958). Принадлежность минерала к политипу 1М позволяет рассчитать кристаллохимическую формулу глауконита на 12 анионов по методу Соболева (Соболев, 2007): $\mathrm{K}_{0.32} \mathrm{Na}_{0.02} \mathrm{Ca}_{0.13}\left(\mathrm{Al}_{0.12} \mathrm{Fe}^{\mathrm{III}}{ }_{0.61}\right.$ $\left.\mathrm{Fe}^{\mathrm{II}}{ }_{0.1} \mathrm{Mg}_{0.46}\right)\left(\mathrm{Al}_{0.6} \mathrm{Si}_{3.4} \mathrm{O}_{10}\right)(\mathrm{OH})_{2} \cdot \mathrm{nH}_{2} \mathrm{O}$.

Глауконит характеризуется сложным составом октаэдров, в который входят три главных элемента Al, Fe, Mg. Межслоевые промежутки заполняются калием, натрием и кальцием, которые являются обменными катионами. Согласно структурной формуле преобладающим катионом в октаэдрической позиции является Fe(III), что свидетельствует о малой дефектности в октаэдрах. Вместе с тем, измененность глауконита подтверждается пониженным содержанием калия и магния и повышенным содержанием железа(III).

На ИК спектрах образца (рис. 2) обнаружена одна сильная полоса поглощения при $1072 \mathrm{~cm}^{-1}$, относящаяся к валентным колебаниям Si-O связей, проявляются три полосы деформационных колебаний Si-O-Me ${ }^{2+,(3+)}$ с максимумами 440, 470, $518 \mathrm{~cm}^{-1}$. а полоса $\mathrm{Al}-\mathrm{OH}$, приходящаяся на $920 \mathrm{~cm}^{-1}$ 


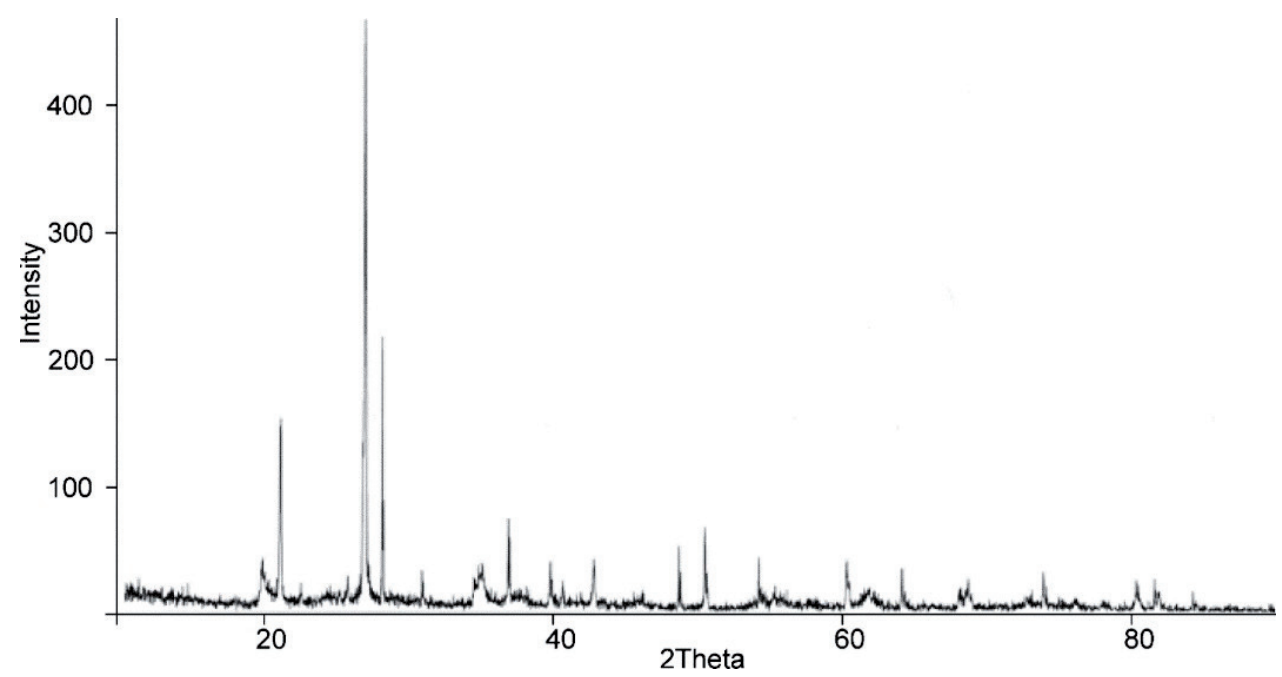

Рис. 1. РФА глауконита. Fig. 1. XRD pattern of glauconite.

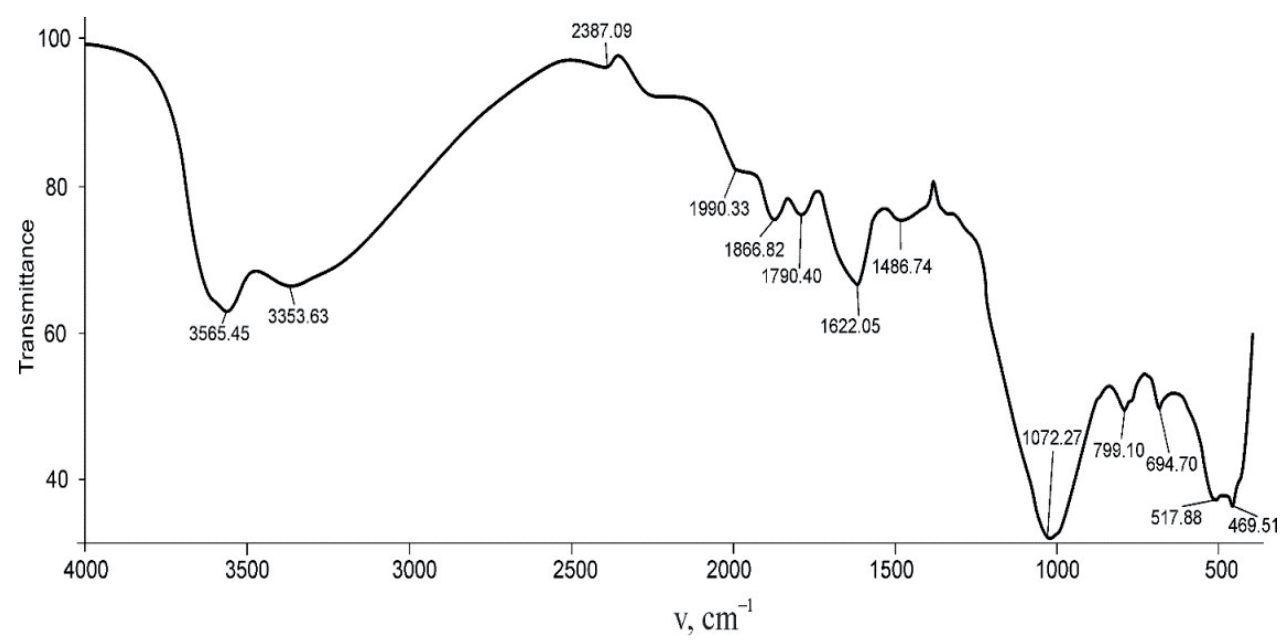

Рис. 2. ИК спектр глауконита. Fig. 2. FTIR spectrum of glauconite.

отсутствует, что объясняется преобладанием железа (III) в октаэдрическом слое. Преобладание железа в октаэдрическом слое проявляется и в области валентных колебаний $\mathrm{OH}^{-}$групп $\left(3600-3000 \mathrm{~cm}^{-1}\right)$. Интенсивность первой полосы с максимумом в области $3565 \mathrm{~cm}^{-1}$, относящейся к колебаниям $\mathrm{HO}-\mathrm{Fe}^{3+}$ значительно выше, чем колебания в области $3353 \mathrm{~cm}^{-1}$, характеризующей HO-Al связи. При нагревании минерала характер спектров сохраняется, но изменяется интенсивность линий, относя-

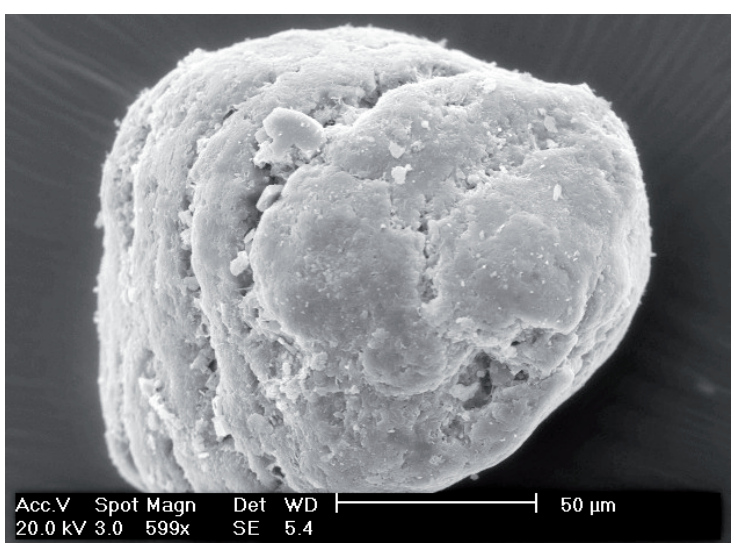

Рис. 3. SEM-изображение зерна глауконита.

Fig. 3. SEM-image of glauconite particle. щаяся к колебаниям $\mathrm{Si}-\mathrm{O}-\mathrm{Me}^{2+,(3+)}$ по мере изменения соотношения $\mathrm{Fe}^{2+}: \mathrm{Fe}^{3+}$.

Микрофотография глауконита (рис. 3), полученная с помощью сканирующего электронного микроскопа, позволяет оценить морфологию минерала. Очевидно, что зерно глауконита имеет достаточно правильную окатанную форму с выкрошенными по трещинам краями, что может свидетельствовать о начальных процессах развития монтмориллонизации. Наблюдаемое радиальное расположение пластин позволяет отнести зерна минерала к сферолитам.

Использование глинистых минералов в качестве сорбентов осложнено процессами их частичного растворения, что вызывает опасность вторично- 


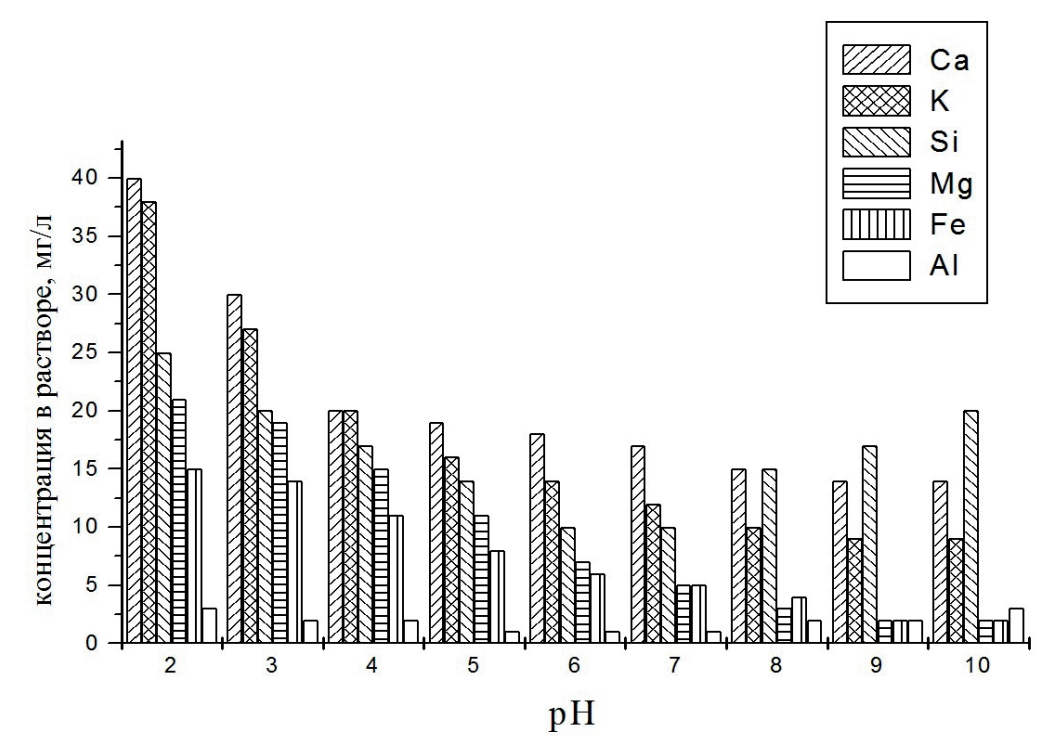

Рис. 4. Концентрация структурообразующих катионов в растворе в зависимости от $\mathrm{pH}$ среды.

Fig. 4. Effect of $\mathrm{pH}$ on dissolution of glauconite in aqueous medium.

го загрязнения очищаемой воды структурообразующими катионами минерала. Поэтому предварительно проверили растворение глауконита при различных рН среды (рис. 4).

Согласно приведенным данным на рисунке 5, наибольшее выщелачивание структурообразующих катионов глауконита наблюдается для межслоевых $\mathrm{Ca}^{2+}$ и $\mathrm{K}^{+}$в кислой области $\mathrm{pH}$, поскольку контролируется ионным обменом между катионами и протоном. При переходе в щелочную область выход межслоевых катионов постепенно уменьшается и не изменяется при $\mathrm{pH}>8$. Для алюминия и кремния минимальная степень выщелачивания приходится на нейтральную область $\mathrm{pH}$, что отражает их амфотерные свойства. В целом, зависимость растворения минерала от $\mathrm{pH}$ среды это комбинация поведения поверхностных центров. Для глауконита железо и магний-гидроксильные центры сосредоточены на краях, а силоксановые и алюминольные центры оккупируют базальный план. Они имеют различные позиции в кристаллической структуре, и следовательно, обладают различной энергией активации растворения. Поверхность оксидов характеризуется определенным значением $\mathrm{pH}$ точки нулевого заряда $\left(\mathrm{pH}_{\text {т.н.3. }}\right.$ ). Для $\mathrm{SiO}_{2}$ и $\mathrm{Al}_{2} \mathrm{O}_{3}$ эти величины 2 и 9.1 соответственно (Parks,

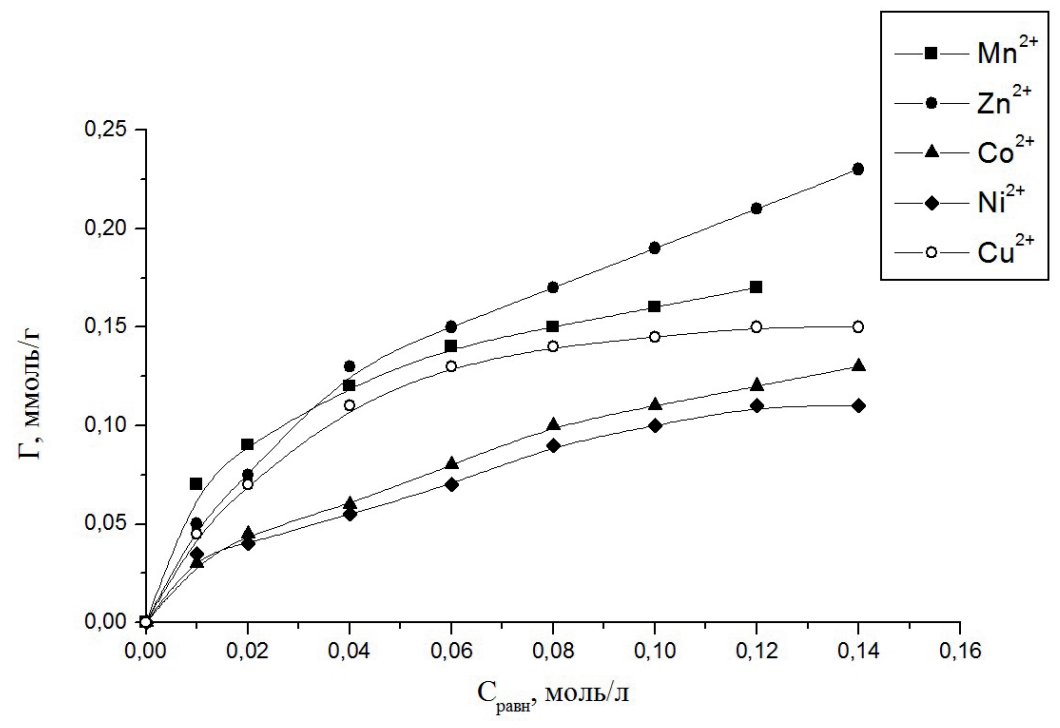

Рис. 5. Изотермы сорбции ионов металлов на глауконите.

Fig. 5. Sorption isotherms of studied metal ions on glauconite. 
1965). Это означает, что в кислой области рН алюминиевые поверхностные центры строго протонированы $\left(>\mathrm{Al}-\mathrm{OH}_{2}^{+}\right)$и более реакционноспособны, чем незаряженные кремниевые поверхностные центры (> Si-OH). В щелочной области $\mathrm{pH}$ главную роль играют депротонированные $>\mathrm{SiO}^{-}$группы. Следовательно, растворение тетраэдрических слоев глауконита в зависимости от рН среды определяется двумя процессами: в кислой области растворение лимитировано выщелачиванием кремния, в щелочной - выщелачиванием алюминия. Поведение октаэдрических катионов можно проследить на примере железа и магния. Точка нулевого заряда для $\mathrm{Fe}_{2} \mathrm{O}_{3}-8.5$, для $\mathrm{MgO}-12.3$ (Parks, $1965)$ и поэтому выщелачивание октаэдрических катионов наиболее активно протекает в кислой области $\mathrm{pH}$. При переходе в нейтральную и щелочную область на поверхности слюды доминируют неактивные $>\mathrm{FeOH}$ и $>\mathrm{MgOH}$ комплексы и выщелачивание катионов резко снижается. Повышенная миграционная способность октаэдрических катионов в кислой среде свидетельствует о том, что в октаэдрических слоях связь катионов с кислородом более слабая, чем в тетраэдрических слоях. Поскольку октаэдрические позиции структурно неэквивалентны, то обладают различной энергией. Скорость выщелачивания октаэдрических катионов коррелируется с их ионным радиусом и степенью октаэдрического заполнения. Близость ионных радиусов железа и магния (78 и $72 \AA$ ) и их положение в слоевой структуре предполагает конгруэнтное растворение этих компонентов. Более быстрое растворение магния по сравнению с железом определяется энергией активации поверхностного комплекса (Wieland, Wehrli, Stumm, 1988). Очевидно, что сорбционные свойства минерала будут определяться как ионообменными реакциями, так и реакциями поверхностного комплексообразования. В нейтральной и щелочной области $\mathrm{pH}$ поверхность минерала заряжена отрицательно и может присоединять положительно заряженные катионы из растворов. В кислой области $\mathrm{pH}$ поверхность заряжена положительно, и, следовательно, доминирующими будут ионообменные реакции.

Сорбционная способность глауконита изучалась по отношению к ионам тяжелых металлов. Для исследований были выбраны катионы Zn (II), Mn (II), Cu(II), Co(II), Ni(II).

Как видно из представленных результатов (рис. 5), исследуемый материал обладает хорошей сорбционной способностью по отношению к выбранным ионам. Количество поглощенного катиона металла закономерно увеличивается по мере возрастания его содержания в исходном растворе. Судя по показателю степени сорбции, исследуемый ионит обеспечивает практически полную

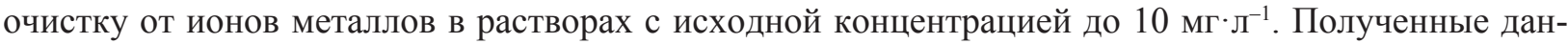
ные позволяют установить ряд селективности для выбранных катионов металлов на глауконите: $\mathrm{Zn}^{2+}>\mathrm{Mn}^{2+}>\mathrm{Cu}^{2+}>\mathrm{Co}^{2+}>\mathrm{Ni}^{2+}$.

\section{Выводы}

Рассмотрены структурные особенности, физико-химические и сорбционные свойства глауконита месторождения Центральное. Методами химического анализа, РФА и ИК-спектроскопии показано, что преобладающим катионом в октаэдрической позиции минерала является $\mathrm{Fe}(\mathrm{III})$, что свидетельствует о малой дефектности в октаэдрах. Вместе с тем, измененность глауконита подтверждается пониженным содержанием калия и магния и повышенным содержанием железа (III). Показано, что наибольшее выщелачивание структурообразующих катионов глауконита наблюдается в кислой области рН. Исследуемый материал обладает хорошей сорбционной способностью по отношению к катионам тяжелых металлов металлам. Установлен ряд селективности для выбранных катионов металлов на глауконите: $\mathrm{Zn}^{2+}>\mathrm{Mn}^{2+}>\mathrm{Cu}^{2+}>\mathrm{Co}^{2+}>\mathrm{Ni}^{2+}$.

\section{Литература}

1. Вениг С.Б., Чернова Р.К., Сержантов В.Г., Сплюхин В.П., Переспелова М.А., Селифонова Е.И., Наумова Г.Н. Определение сорбционных характеристик глауконита при извлечении фармацевтического препарата из водных сред // Вестник Московского университета. 2017. № 58 (5). С. 260-66.

2. Вигдорович В.И., Цыганкова Л.Е., Филиппова О.Б., Шель Н.В., Есина М.Н., Фролов А.И. Глауконит как экологически безопасный сорбент для умягчения питьевой и питательной котельной воды // Химическая Технология. 2016. № 3 (17). С. 129-37.

3. Кацнельсон Ю.Я., Алексаньян О.М., Волошина А.М. Глауконитсодержащие микроконцентрации как поглотители радионуклидов // Минералогия и Геохимия Глауконита. 1981. С. 80-89. 
4. Соболев В.С. Введение в минералогию силикатов. 2-е изд. Новосибирск. Изд-во: Гео. 2007. 229 с.

5. Яншин А.Л. Глауконит в современных, нижнепалеозойских и докембрийских отложениях. М. Изд-во: Наука. 1971. 199 с.

6. Bruneel Y., Van Laer L., Brassinnes S., Smolders E. Radiocaesium sorption on natural glauconite sands is unexpectedly as strong as on Boom Clay // Science of The Total Environment. 2020. 720. 137392. https://doi. org/10.1016/j.scitotenv.2020.137392.

7. Burst J.F. Mineral heterogeneity in «glauconite» pellets // The American Mineralogist. 1958. V. 43. P. $481-97$.

8. Hao O.J., Tsai C.M., Huang C.P. The removal of metals and ammonium by natural glauconite // Environment International. 1987. V. 13 (2). P. 203-12.

9. Martemianov D., Plotnikov E., Rudmin M., Tyabayev A., Artamonov A., Kundu P. Studying glauconite of the Bakchar deposit (Western Siberia) as a prospective sorbent for heavy metals // Journal of Environmental Science and Health, Part A. 2020. V. 55 (11). P. 1359-65. https://doi.org/10.1080/10934529.2020.1794686.

10. Naghipour D., Taghavi K., Ashournia M., Jaafari J., Movarrekh R.A. A study of Cr(VI) and $\mathrm{NH}_{4}^{+}$adsorption $^{-}$ using greensand (glauconite) as a low-cost adsorbent from aqueous solutions // Water and Environment Journal. 2018. V. 34 (1). P. 45-56. https://doi.org/10.1111/wej.12440.

11. Parks G.A. The isoelectric points of solid oxides, solid hydroxides, and aqueous hydroxo complex systems // Chemical Reviews. 1965. V. 65. P. 177-83.

12. Shmandiy V., Rigas T., Kharlamova O., Bezdeneznych L. Research of adsorption properties of glauconitebased composite adsorbents // Journal of Ecological Engineering. 2020. V. 21 (6). P. 147-54. https://doi. org/10.12911/22998993/123245.

13. Stefanova I.G. Natural sorbents as barriers against migration of radionuclides from radioactive waste repositories // Natural Microporous Materials in Environmental Technology. 1999. 362. P. 371-79.

14. Wieland E., Wehrli B., Stumm W. The coordination chemistry of weathering: III. A generalization on the dissolution rates of minerals // Geochimica et Cosmochimica Acta. 1988. V. 52 (8). P. 1969-81. https://doi. org/10.1016/0016-7037(88)90178-0. 